\title{
Erratum
}

\section{Ronald S. Wilson}

University of Louisville School of Medicine, Louisville, Kentucky

In my article "Analysis of Longitudinal Twin Data: Basic Model and Applications to Physical Growth Measures" in Volume 28:93-105 (1979) the footnote to Table 5 on page 100 should read $\sigma \frac{2}{\mathrm{e}}=\sigma \frac{2}{\mathrm{e}} / \mathrm{q}$.

Also, in the equation at the top of page 102, the two separate terms in the denominator should each be multiplied by $(q-1)$, ie,

$$
\sqrt{\frac{1}{\left(\mathrm{p}_{\mathrm{MZ}}{ }^{-2}\right)(\mathrm{q}-1)}+\frac{1}{\left(\mathrm{p}_{\mathrm{DZ}}-2\right)(\mathrm{q}-1)}}
$$

